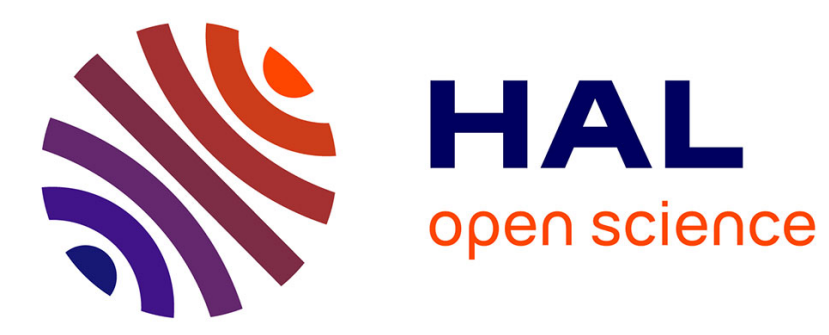

\title{
Viscosity of Metals under Shock-Loading Conditions
}

\author{
V. Mineev, A. Mineev
}

\section{To cite this version:}

V. Mineev, A. Mineev. Viscosity of Metals under Shock-Loading Conditions. Journal de Physique IV Proceedings, 1997, 07 (C3), pp.C3-583-C3-585. 10.1051/jp4:19973100 . jpa-00255384

\section{HAL Id: jpa-00255384 https://hal.science/jpa-00255384}

Submitted on 1 Jan 1997

HAL is a multi-disciplinary open access archive for the deposit and dissemination of scientific research documents, whether they are published or not. The documents may come from teaching and research institutions in France or abroad, or from public or private research centers.
L'archive ouverte pluridisciplinaire HAL, est destinée au dépôt et à la diffusion de documents scientifiques de niveau recherche, publiés ou non, émanant des établissements d'enseignement et de recherche français ou étrangers, des laboratoires publics ou privés. 


\title{
Viscosity of Metals under Shock-Loading Conditions
}

\author{
V.N. Mineev and A.V. Mineev \\ High Energy Density Research Center of the Institute for High Temperature Russian Academy of Science, \\ Izhorskaya 13/19, Moscow 127412, Russia
}

\begin{abstract}
Viscosity of shock-compressed $\mathrm{Al}$ and $\mathrm{Pb}$ was determined at pressures 31-202 $\mathrm{GPa}$ and 35-250 GPa by experimental investigation of the development of small perturbations in the shock wave front. Results of experiment shown that viscosities $\mathrm{A} 1$ and $\mathrm{Pb}$ at pressure $31 \mathrm{GPa}$ and $35 \mathrm{GPa}$ are practically equal and amount to $(2-4) 10^{4} \mathrm{P}$. Under these conditions $\mathrm{Al}$ and $\mathrm{Pb}$ are deformed by $180 \%$ at strain rate of $10^{7} \mathrm{sec}^{-1}$.
\end{abstract}

\begin{abstract}
Résumé: La viscosité de l'Al et du $\mathrm{Pb}$ comprimés par une onde de choc a été déterminée pour des pressions de 31 $202 \mathrm{GPa}$ et 34-250 GPa par l'étude expérimentale du développement des petites perturbations sur le front de l'onde de choc. Les résultats expérimentaux ont montré, que les viscosités de l'Al et du $\mathrm{Pb}$ sous $31 \mathrm{GPa}$ et $34 \mathrm{GPa}$ sont pratiquement identiques derrière le front de l'onde de choc et égales à (2-4) $10^{4} \mathrm{P}$. Dans ces conditions les métaux sont déformés à $180 \%$ pour une vitesse de déformation de $10^{7} \mathrm{sec}^{-1}$.
\end{abstract}

\section{INTRODUCTION}

Models of viscosity-plastic material are used for computer simulation of structure response to high speed impact. Viscosity determine dissipation of energy under strain rate effects. But viscosity of materials specifically metals in extensive range of strain rate is not investigated above strain rates $\dot{\boldsymbol{\varepsilon}}$ $=10^{5} \mathrm{sec}^{-1}$.

We report here the results of an experimental investigation of the viscosity of aluminum and lead in range of strain rates $=(4-80) 10^{6} \mathrm{sec}^{-1}$, compressions above 2 and temperatures above $20000 \mathrm{~K}$.

Viscosity of this metals was determined by an experimental investigated of the development of small disturbances in the shock wave front(SWF). The artifically imposed small perturbations, characterized by a periodicity along the surface of the SWF, constitute on this surface a sort of a "ripple" and bring the substance behind the SWF into oscillatory motion. Coefficients of viscosity were calculated by discovered dispersion of the development of disturbances in the SWF.

\section{EXPERIMENTAL SETUP AND RESULTS}

The experiments were carried out in setup proposed by Sakharov et al [1].

The experimental setups(Fig.1) included: an explosive assembly - the generator of a plane wave in the investigated materials, a disk with grooves with a sinusoidal cross-section profile(to produce harmonic perturbations on the SWF), and a sample in the form of a wedge, in order to record in single experiment the perturbation at distance(or at several consecutive times).

Perturbations in SWF had two wavelengths $\lambda_{1}=1 \mathrm{~cm}$ and $\lambda_{2}=2 \mathrm{~cm}$, and relative(on wavelength) initial amplitudes $\mathbf{a}_{0} / \lambda=0.05-0.2$ in two geometrically similar, with respect to $\lambda$, experimental arrangements. ao is initial disturbance amplitude on SWF. The SWF profile against time was detected by using a high speed photo camera. Figure 2 give typical curves showing the development of disturbances in SWF in selfsimilar coordinates: amplitude $-y=a(t) / a_{0}$, path traveled by SWF $\mathrm{x}=\mathrm{S}(\mathrm{t}) / \lambda$, where $\mathrm{a}(\mathrm{t})$ and $\mathrm{S}(\mathrm{t})$ are, respectively, the running amplitude and path traveled by $\mathrm{SWF}$. Experiment and Zadel's theory of this experiment[2] have shown that, when the experimental setup is geometrical similar with respect to the wavelength of the perturbations, the effect of the viscosity leads to a phase shift $\Delta x$ between the experimental curves $y=f(x)$ with different wavelength $\lambda_{1}$ and $\lambda_{2}$. 


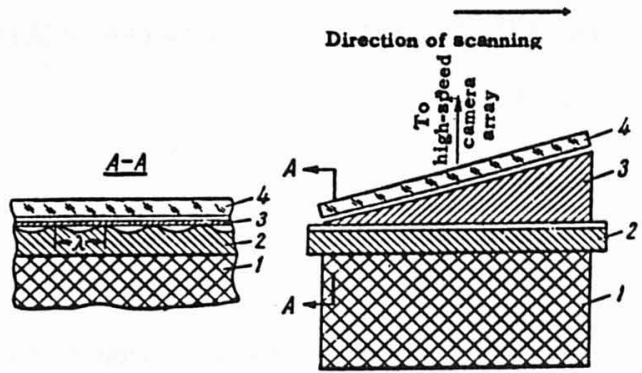

FIG. 1. Experimental arrangement: 1) high-explosive charge; 2) 3) a disk and a wedge of the material under investigation; 4) Perspex plate.

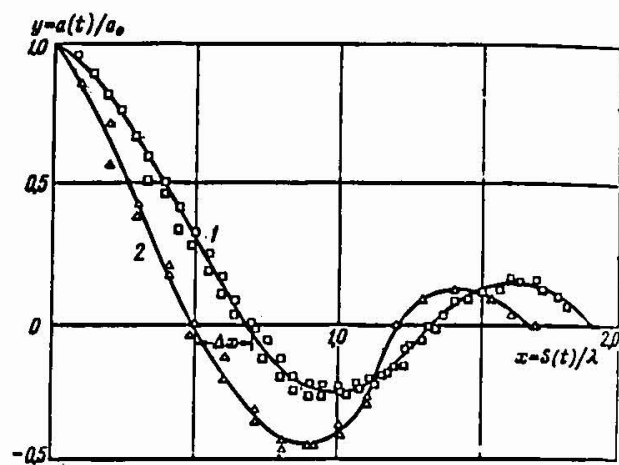

FIG. 2. Experimental curves showing the development of disturbances in a shock-wave front in aluminum $(m-1)$ at $p=310$ kbar: 1) $\left.\lambda=2 \mathrm{~cm}, a_{\sigma} / \lambda=0.139 ; 2\right) \lambda=1 \mathrm{~cm}$,

$a_{a} / \lambda=0.139$. $\Delta x$ is the phase shift between the experimental curves.

In some experiments the initial densitiy $\left(\rho_{0}\right)$ of aluminum was less than the normal densiry $\left(\rho_{0}\right)$ by a factor $m=\rho_{0} / \rho_{00}$. This made it possible to investigate the viscosity of aluminum in the density range from 0.59 to $15.5 \mathrm{~g} / \mathrm{cm}^{3}$ at temperatures from 630 to $1010 \mathrm{~K}$.

Geometrical similar explosive devices in with a thin, steel impactor of spherical geometry was accelerated by explosion products of converging detonation waves were used for investigation viscosity of aluminum and lead from above pressure $100 \mathrm{GPa}$ [3]. In this case a spherical shell with grooves with a sinusoidal cross-section profile(to produce harmonic perturbations on the SWF), and a sample in the form of a spherical wedge, in order to record in single experiment the perturbations at distance(or at several consecutive times).

Dynamic viscosity $\eta$ was calculated from the formula

$$
\eta=\rho \mathrm{D} \Delta \mathrm{x} / \mathrm{k}\left(1 / \lambda_{1}-1 / \lambda_{2}\right) \text {, }
$$

where $\rho$ is the density of the substance behind an unperturbed SWF; D is the waye velocity of an unperturbed $S W F ; \mathrm{k}$ is a constant $(\cong 10)$ calculated as described by Zaidel '[2].

Results of experiment are given in Table( $P$ - pressure, $T$ - temperature behind a SWF). In the calculation of the parameters of a given substance behind a SWF, we used the equations of state for aluminum and lead given by Al'tshuler[4].

Table. Results of experiment.

\begin{tabular}{|l|l|l|l|l|l|}
\hline Substance & $\mathrm{m}$ & $\mathrm{P}, \mathrm{GPa}$ & $\rho, \mathrm{g} / \mathrm{cm}^{3}$ & $\mathrm{~T}, \mathrm{~K}$ & $\eta 10^{4}, \mathrm{P}$ \\
\hline $\mathrm{Al}$ & 1 & 31 & 3.41 & 630 & $2 \pm 0.5$ \\
\hline & 1 & 68 & 3.85 & 1600 & $10 \pm 4$ \\
\hline & 1 & 105 & 423 & 3500 & $7 \pm 2$ \\
\hline & 1 & 202 & 4.96 & 10100 & $<2$ \\
\hline & 1.23 & 27.5 & 2.6 & 1700 & $1 \pm 0.5$ \\
\hline & 1.43 & 24.5 & 2.06 & 2600 & $<0.2$ \\
\hline & 4 & 12 & 0.59 & 4600 & $<0.2$ \\
\hline $\mathrm{Pb}$ & 1 & 35 & 15.5 & 1400 & $3.7 \pm 1.4$ \\
\hline & 1 & 41 & 15.7 & 1700 & $15 \pm 2$ \\
\hline & 1 & 124 & 18.8 & 7000 & $<30$ \\
\hline & 1 & 250 & 23.5 & 20000 & $<13$ \\
\hline
\end{tabular}




\section{DISCUSSION}

Results of experiment showed that viscosities of aluminum and lead at pressures of $31-35 \mathrm{GPa}$ behind a SWF are practically equal and amount to $(2-4) 10^{4} \mathrm{P}((2-4) \mathrm{KPa} \cdot \mathrm{sec})$.

The order of magnitude of the deformation behind a disturbed SWF is given by $\varepsilon=2 \pi \mathrm{a}_{0} / \lambda$ and the strain rate by $\dot{\varepsilon}=2 \pi \varepsilon \mathrm{D} / \lambda$. In our experiments $\varepsilon=30-130 \%$ and $\dot{\varepsilon}=4 \cdot 10^{5}-20 \cdot 10^{6} \mathrm{sec}^{-1}$.

The viscosity of aluminum at a pressure of $31 \mathrm{GPa}$ is independent of the strain rate, at least in the range from $4 \cdot 10^{5}$ to $8 \cdot 10^{6} \mathrm{sec}^{-1}$. It has been shown that aluminum behind a SWF in this strain rate range is Newton's liquid.

Decreasing viscosity of aluminum and lead with increasing of pressure $(m=1)$ or temperature $(m>1)$, possible, testify about melting of substances behind SWF.

Now we have results of three-group experiments for investigation of viscosity of aluminum under high velocity deformation.

Il'yshin[5], Stepanov and Vashenko[6] investigated viscosity of aluminum in conditions high speed impact of rods and core. They have shown that, under dynamic loading conditions, characterized by strain rate $=(6-60) 10^{2} \mathrm{sec}^{-1}$, aluminum behave as viscous liquids with coefficients of dynamic viscosity about $\eta=(3-8) 10^{4} \mathrm{P}$. Trunov[7] shown that viscosity of aluminum under implosion shells is about $0.8 \cdot 10^{4} \mathrm{P}\left(\dot{\boldsymbol{e}} \cong 10^{5} \mathrm{sec}^{-1}\right)$. Deribas[8] shown that viscosity of aluminum in shock-wellding condition $\left(\dot{\varepsilon} \cong 10^{5} \mathrm{sec}^{-1}\right)$ is about (3-8) 104 $\mathrm{P}$. I n conditions [5-8] aluminum was in not melting state.

So we can made conclusion that viscosity of aluminum under range strain rate from $6 \cdot 10^{2} \mathrm{sec}^{-1}$ to $2 \cdot 10^{7} \mathrm{sec}^{-1}$ do not depend from strain rate and are practically equal and amount to $10^{4}-10^{5} \mathrm{P}$.

\section{CONCLUSIONS}

Experiment and theory shown that method investigation of viscosity of metals under shock-wave conditions by means of measurement of the development of small perturbations in the shock wave front can reveal coefficients of viscosity order $10^{4}-10^{5} \mathrm{P}$. This shock-wave viscosity measurement method was subjected critical analysis by Miller and Ahrens[9]. Geometrical similarity of the explosive devices and small of harmonical perturbations are excluded of methodological errors, for example, influence strength of substance behind SWF on a phase shift between the experimental curves with different wavelength.

Results our paper make it possible to assume that shocked aluminum and lead behaves as a viscous Newtonian fluid range strain rate from $6 \cdot 10^{2} \mathrm{sec}^{-1}$ to $2 \cdot 10^{7} \mathrm{sec}^{-1}$ do not depend from strain rate.

So we can made conclusion that viscosity of aluminum and lead under range strain rate from $6 \cdot 10^{2}$ $\mathrm{sec}^{-1}$ to $2 \cdot 10^{7} \mathrm{sec}^{-1}$ do not depend from strain rate and are practically equal and amount to $10^{4}-10^{5} \mathrm{P}$.

\section{REFERENCES}

[1] Sakharov A.D., Zaidel` R. M., Mineev V. N., Oleinik A.G., DAN SSSR(in Russian) 159(1964) 1019-1022.

[2] Zaidel' R. M., PMTF(in Russian) 4(1967) 30-35.

[3] Altshuler L.V., Krupnikov K.K., Panov V. N., Trunin R.F., UFN(in Russian) 166(1966) 575581 .

[4] Al'tshuler L.V., Sov. Phys. Usp 8(1965) 52- 100.

[5] Il'yshinA. A., Uchenye zapishki MGU(in Russian) 39(1940) 11-14.

[6] Stepanov G.V., Vashenko A. P., Problemy prochnosty(in Russian) 10(1984) 109-113

[7] Trunov V.L., "Dynamika sploshnoi sredy"(in Russian),

Institut Gidrodinamiki, Novosibirsk, 1979, pp. 69-79.

[8] Deribas A.A., Physika shock-wellding(in Russian), Nayka, Novosibirsk, 1972, pp. 139-149.

[9] Miller G. H., Ahrens T. J., Rev. of Modern Phys. 63(1991) 919-948. 